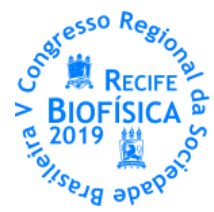

\title{
A UTILIZAÇÃO DE ATIVIDADES PRÁTICAS EM AULAS DE FISIOLOGIA SENSORIAL: OLFATO E GUSTAÇÃO
}

\author{
Leonardo Messias Félix de Almeida ${ }^{1 *}$, Estefani Santana do Nascimento², Cristiane Maria Varela de Araújo de Castro³, \\ ${ }^{1}$ Laboratório de Ecofisiologia e Comportamento Animal, Departamento de Morfologia e Fisiologia Animal, UFRPE \\ *lecaecotoxufrpe@gmail.com
}

\section{INTRODUÇÃO}

Segundo Domingos (2013), as ciências estão presentes no cotidiano de forma tão natural que muitas vezes nem percebemos, por exemplo, ao realizar consertos simples em casa como trocar uma tomada, envolvem conhecimentos sobre circuitos elétricos; ler uma bula de remédio e interpretar uma conta de luz são outros exemplos do uso de conhecimentos básicos em ciências. Há também os temas que envolvem decisões políticas, como aborto, mudanças climáticas, alternativas energéticas, transgênicos, tecnologia nuclear, produção de alimentos, abastecimento público, poluição, dentre outros. A lista dos assuntos que trazem a ciência para nosso cotidiano é enorme.

Um dos ramos da biologia é a Fisiologia Humana, uma disciplina de extrema importância para os alunos, por incluir todos os sistemas fisiológicos permitindo que os mesmos conheçam melhor seu corpo, o funcionamento dele, assim como algumas doenças. Ela apresenta processos, termos, ciclos fisiológicos que muitas vezes não são de fácil compreensão, pela sua complexidade conceitual, pela didática adotada entre outros fatores.

No entanto Barbão e Oliveira (2010) apontam que alunos de ensino médio de escolas públicas demonstram dificuldade na aprendizagem dos termos da Biologia. E para que se compreenda a fisiologia é de suma importância o conhecimento sobre o nome e localização de estruturas e órgãos, o que permitirá a visão integrada do funcionamento do organismo.

Em termos de Fisiologia Humana, o estudante deve ter conhecimento a respeito do funcionamento dos órgãos, bem como a capacidade de estabelecer a relação entre os diferentes aparelhos e sistemas, e entre o corpo e o ambiente, de modo a preservar o equilíbrio que caracteriza o estado de saúde (BORGES, 2016).

Diante do exposto anteriormente, vemos a grande necessidade do ensino de ciências, porém, não de uma forma descontextualizada e muitas vezes existindo em um outro mundo que não o nosso. As ciências ensinadas nas escolas precisam ser as mesmas que nos deparamos no dia a dia, para que assim, o aluno passe da condição de repetidor para a condição de transformador.

Pensando na precariedade da educação como sendo bancária, Freire (2005) cita a educação problematizadora, como um meio para a liberdade dos oprimidos, um meio que reforça a mudança, sendo essa um esforço através do qual os homens se tornam críticos e percebem "como estão sendo no mundo com que e em que se acham".

Para Andrade e Massabni (2011), uma forma de se alcançar um ensino de qualidade é na utilização de atividades práticas, das quais podemos citar: estudo do meio, experimentação, visita com observações, entre outras, que são fundamentais para o ensino de Ciências.
Se debruçando nas literaturas relacionadas à didática do ensino de Ciências é perceptível que a maior parte dos professores ainda não fazem uso de atividades práticas, por alegarem não ter materiais necessários, espaço, hora/aula suficiente, entre outros motivos. Outras vezes, usam roteiros já padronizados e prontos como atividade prática sem atingir seus pré-requisitos que consiste em levar o aluno a refletir, debater e construir o aprendizado significativo.

Em contraponto a literatura mostra que os alunos estão perdendo o interesse pela escola ao longo dos anos e quando se trata de ciências, matemática e suas tecnologias, matérias que estão enriquecida de assuntos abstratos, e por muitas vezes ensinadas de forma desvinculada da vivencia do aluno, acarretando um aprendizado não associativo, cansativo e não satisfatório provocando um insucesso escolar.

Outro ponto fundamental é que, apesar de os PCNs (Parâmetros Curriculares Nacionais) enfatizarem a importância do ensino construtivista, aprendizagem centrada no aluno, desenvolvimento de capacidade de investigação etc. e muitos professores saberem discursarem sobre a maioria demonstra dificuldade para materializar tais noções em sala de aula (CERRI \& TOMAZELLO, 2008).

Contudo ao professor cabem dois papeis importantes dentro da ótica construtivista. 0 primeiro é o de professor tutor, no qual o docente é um guia de aprendizagem e assume uma função intermediária entre uma ação totalmente dirigida pelo professor e uma atividade auto dirigida pelo aluno. 0 segundo é o de professor assessor, que assume muito mais a função de questionar do que de dar respostas; provoca, ainda, a reflexão e a solução autônoma de problemas que possam surgir na realização de projetos que os alunos proponham realizar (MOREIRA \& DINIZ, 2015).

Uma das atividades práticas que permeiam os assuntos de fisiologia sensória uma das subáreas da fisióloga humana são as relacionadas a percepção de sabor. Para a percepção plena do sabor, se faz necessário a integração de vários estímulos sensoriais, dentre eles podemos citar: olfato, gustação, visão e tato; além disso, a integração desses estímulos no encéfalo e o resgate da memória relacionada ao que se está experimentando é de fundamental importância.

Por isso o presente trabalho tem como objetivo avaliar a interferência da memória olfativa na percepção e intensidade do sabor, observar se a imagem e a cor interferem na percepção do sabor, assim como verificar a viabilidade e contribuição das atividades práticas envolvendo olfato e visão nas aulas de fisiologia sensorial. 


\section{MATERIAIS E MÉTODOS}

Foi elaborada uma atividade prática com o intuito de testar qual a influência da memória olfativa e da visualização de imagens relacionadas a cores na identificação do sabor. Após a participação de 19 alunos, do curso de Licenciatura em Ciências Biológicas da UFRPE, na atividade prática, os mesmos responderam um questionário sobre a utilização dessa prática em aulas de ciências e biologia, para avaliar a viabilidade da inclusão de atividades estimulantes aos alunos do ensino médio.

No primeiro teste, foram utilizadas 4 garrafas de água mineral vazias e lavadas nas quais foram adicionados: molho de tomate, orégano, manga e café. As mesmas foram embrulhadas em papel alumínio para não expor o conteúdo. Os alunos chegavam, individualmente no local do teste, que ocorreu no Laboratório de Fisiologia Animal do Departamento de Morfologia e Fisiologia Animal da UFRPE, os quais eram vendados com um tapa olho preto. Cada participante era exposto a um cheiro de cada vez, após sentir o primeiro cheiro, ele recebia $2 \mathrm{~mL}$ de uma solução de água, açúcar, sal e suco de limão (1L, $10 \mathrm{~g}, 1 \mathrm{~g}$ e $4 \mathrm{~mL}$, respectivamente). Após provar a solução, era perguntado os gostos (salgado, doce, amargo ou azedo) que sentia e a intensidade. Isso era repetido a cada cheiro. Foi avaliado se os gostos e a intensidade mudavam com a percepção dos diferentes cheiros. A solução utilizada era a mesma para todos os cheiros.

Após os alunos passarem no primeiro teste, eles eram conduzidos para o segundo teste, que consistia na exposição de duas imagens com colocaração semelhante à do líquido ofertado. As imagens utilizadas foram: Sopa de abobora e laranja associadas a oferta da solução laranja (G1); carne vermelha e morango associadas a oferta do líquido de coloração vermelha (G2); chocolate e tamarindo associado a oferta de uma solução marrom (G3) e por fim a imagem de pimentão e limão associado á oferta de uma solução verde (G4). Todas as soluções ofertadas eram iguais a do teste 1 , feitas a partir de uma mistura de água, açúcar, sal e suco de limão (1L, $10 \mathrm{~g}, 1 \mathrm{~g}$ e $4 \mathrm{~mL}$, respectivamente), a única diferença entre elas era a cor do corante, que se assemelhava ao da imagem mostrada. É importante ressaltar que após o participante fixar os olhos, nas duas imagens por alguns segundos, foi ofertado a ele $2 \mathrm{ml}$ da solução e solicitado que ao descrever sua resposta continuasse olhando para as imagens.

Por fim foi distribuído um questionário a fim de que as cobaias pudessem avaliar a prática aplicada a nível de custo e viabilidade de aplicação nas aulas de fisiologia humana.

\section{RESULTADOS E DISCUSSÃO}

Após análise dos resultados quanto a percepção e intensidade dos gostos nos diferentes cheiros (teste 1), foi possível verificar que $89,5 \%$ dos participantes relataram estar sentindo gostos diferentes nas amostras experimentadas após a experiencia olfativa, ou seja, os cheiros estavam induzindo o participante a sentir diferentes gostos básicos. Apenas 10,5\% disseram estar provando a mesma amostra após sentirem os diferentes cheiros. Com relação a intensidade, $100 \%$ dos participantes relataram diferenças na intensidade de sabor da amostra entre um cheiro e outro, mesmo essa amostra sendo igual.

No que se refere a observação da interferência da imagem e da cor na percepção do sabor (teste 2 ) os resultados mostraram que $89,47 \%$ após fixarem os olhos nas imagens laranjas e experimentarem o líquido laranja, disseram que era suco de laranja (Figura 1); que $78,94 \%$ ao degustarem a solução vermelha associado a observação das imagens vermelhas, afirmaram ser suco de morango,(Figura 2); 52,63\% após a observação da imagem marrom e experimentação da solução marrom, disseram que era suco de tamarindo (Figura 3 ) e que $68,42 \%$ dos experimentadores afirmaram ser suco de limão após perceberem o sabor da solução verde em meio a observação das imagens de cor verde (Figura 4).

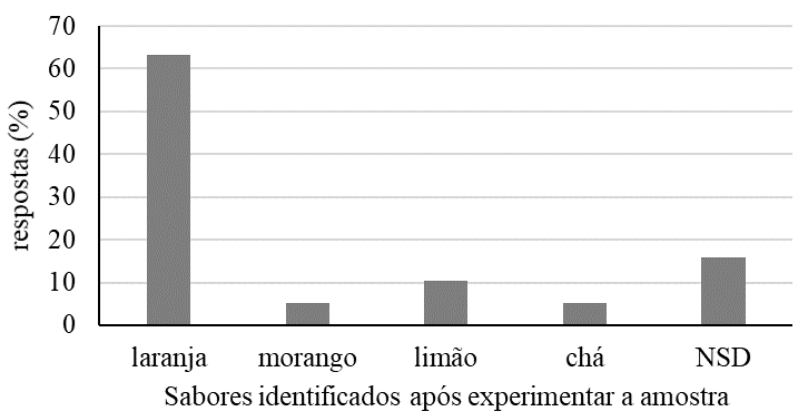

Figura 1. Percentual de pessoas que identificaram os sabores: laranja, morango, limão, chá e Não Dei Dizer, após o teste com associação da visão e do paladar (G1).

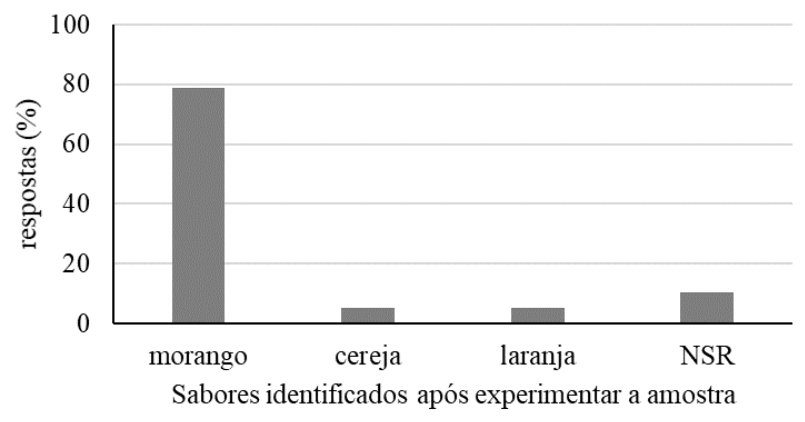

Figura 2. Percentual de pessoas que identificaram os sabores: morango, cereja, laranja e Não Dei Dizer, após o teste com associação da visão e do paladar (G2).

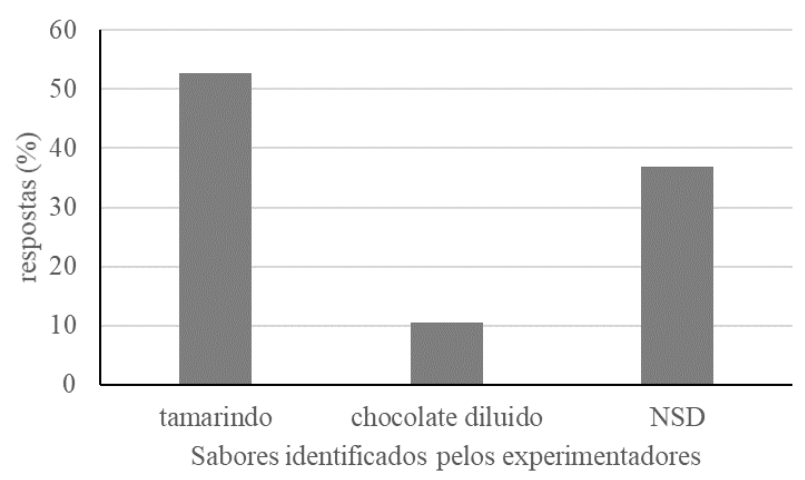

Figura 3. Percentual de pessoas que identificaram os sabores: Tamarindo, chocolate diluído e Não sei dizer, após o teste com associação da visão e do paladar (G3).

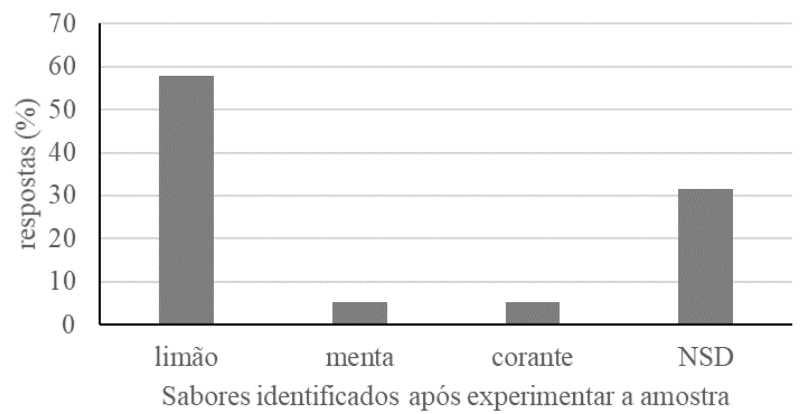

Figura 4. Percentual de pessoas que identificaram os sabores: limão, menta, corante e Não sei dizer, após o teste com associação da visão e do paladar (G4). 
No que se refere a ficha avaliativa sobre a prática aplicada, $100 \%$ dos alunos da licenciatura em ciências biologicas submetidos ao teste, usariam o experimento nas suas aulas de fisiologia e consideram o experimento viavel a ser aplicado inclusive em escola publica pelo seu baixo custo.

Fala et al. (2010) ressalta que é necessário elaborar propostas de aulas experimentais ou adaptar algumas metodologias já existentes, porém pouco utilizadas, que, além de causarem inquietações e reflexões, possam instigar os alunos e, principalmente, ampliar e/ou modificar suas explicações iniciais para os fatos e fenômenos que fazem parte do seu cotidiano (FALA et al., 2010).

Para que o estudante aprenda de modo significativo - conectando e inter-relacionando conceitos, deve estar motivado para a disciplina e reconhecer a importância dela para a sua vida futura. Se assim não for, o estudante pode achar que é mais cômodo e mais fácil memorizar alguns fatos e fórmulas, para esquecê-los logo em seguida (PRINGOL \& GIANNOTTI, 2008).

\section{CONCLUSÕES}

Percebemos que a memória olfativa interfere na percepção do sabor, assim como em sua intensidade. Observamos também que a imagem sugestiona a memória do sabor, uma vez que muitos voluntários ao tomarem a solução acreditavam estar sentindo o doce do suco de morando, de laranja, o amargo da tamarindo e o azedo do limão, no entanto todos os as soluções eram iguais.

Por isso fazer aulas práticas com matérias de baixo custo podem contribuir para o processo ensino-aprendizagem assim como possibilitar debates relacionados a integração dos sistemas, que são trabalhados de forma fragmentada, no entanto funcionam de forma integrada.

\section{REFERÊNCIAS}

ANDRADE, M. L. F.; MASSABNI. M. V. O desenvolvimento de atividades práticas na escola: um desafio para os professores de ciências. Ciência \& Educação, v. 17, n.4: 835-854. 2011.

BARBÃO, A. J. M.; OLIVEIRA, I.G. Utilização e compreensão da nomenclatura biológica por alunos do ensino médio da escola estadual Wilson de Almeida - Nova Olímpia/MT. In Anais do IV Fórum de educação e diversidade. Livro Digital IV. Fórum de Educação e Diversidade, p. 1-5, 2010.

BORGES, G. A.; LIMA. C. O. C.; GRAJEIRO, E. M.; SARINHO, V. T.; BITTENCOURT, R. A. Body: Um Jogo Digital Educacional de Tabuleiro na Área de Fisiologia Humana. XV SB Games, São Paulo, 2016.

CERRI, Y. L. N. S.; TOMAZELLO, M. G. C. Crianças aprendem melhor ciências por meio da experimentação? Em: Pavão A.C. e Freitas, D. (Orgs). Quanta ciência há no ensino de ciências, p.71-79. São Carlos: Editora UFSCar, 2008.

DOMINGOS, M.D. Por que todos precisamos aprender ciências? 2013. Disponível em: <http://porvir.org/por-todos-precisamosaprender-ciencias/> acessado em: 30 out. 2017.

FALA, A. M. et al. Atividades práticas no ensino médio: uma abordagem experimental para aulas de genética. Ciências \& Cognição, v. 15, n. 1, abril, 2010.

FREIRE, P. Pedagogia do Oprimido, $43^{\text {a }}$ ed. Rio de Janeiro, Paz e Terra, 2005, p. 82.

MOREIRA, M. L. DINIZ, R. E. S. O laboratório de biologia no ensino médio: infraestrutura e outros aspectos relevantes, 2015. Disponível em: <https://www.researchgate.net/publication/267217969>. Acesso em: 10 set. 2018.

PRIGOL, S GIANNOTTI, S. M. A importância da utilização de práticas no processo de ensino-aprendizagem de ciências naturais enfocando a morfologia da flor. $1^{\circ}$ Simpósio Nacional de Educação: XX Semana da Pedagogia, Cascavel/PR, 2008. 